Research Paper

\title{
The influence of Europa's plumes on its atmosphere and ionosphere
}

\author{
Jiazheng Li ${ }^{\text {a, }}$, Murthy S. Gudipati ${ }^{\text {b }}$, Yuk L. Yung ${ }^{\text {a,b }}$ \\ ${ }^{a}$ Division of Geological and Planetary Science, California Institute of Technology, Pasadena, CA, USA \\ ${ }^{\mathrm{b}}$ Jet Propulsion Laboratory, California Institute of Technology, Pasadena, CA, USA
}

\section{A B S T R A C T}

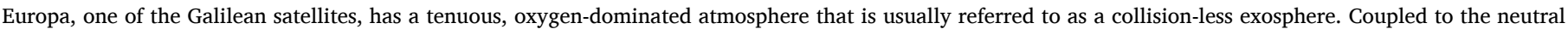

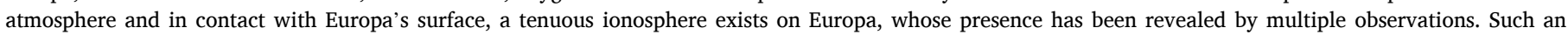

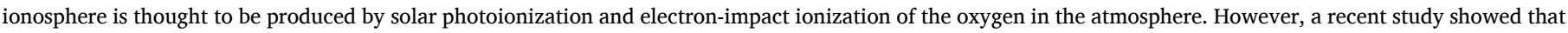

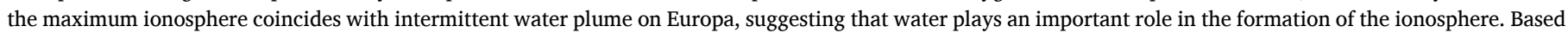

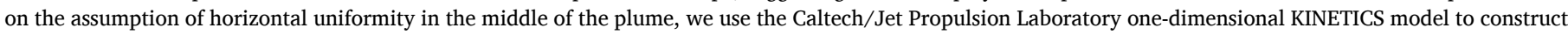

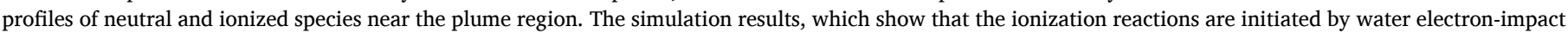

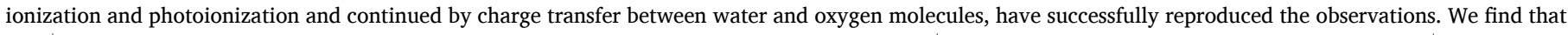

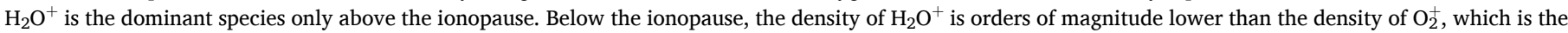

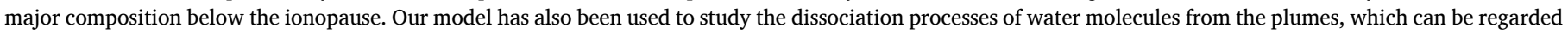
as an alternative source for the oxygen in the atmosphere.

\section{Introduction}

The atmosphere of Europa, which is tenuous and referred to as an exosphere or a surface boundary-layer atmosphere (Johnson et al., 2002), was first detected by Hall et al. (1995) using Hubble Space Telescope observations. Based on observations of oxygen's electronic excitation emissions, the dominant composition of the atmosphere is proposed to be molecular oxygen (Hall et al., 1995), which has been confirmed by several studies (Hall et al., 1995; Saur et al., 1998; Hansen et al., 2005; Smyth and Marconi, 2006; Roth et al., 2016). Atomic oxygen has also been proposed to be present in Europa's atmosphere with a column density of $4.7 \times 10^{12} \mathrm{~cm}^{-2}$, which is two orders of magnitude lower than tsputthe $\mathrm{O}_{2}$ dominated model (Shemansky et al., 2014). It's generally understood that the primary source of the oxygen in the atmosphere is ion sputtering of Europa's surface ice (Brown et al., 1984; Ip, 1996; Ip et al., 1998; Smyth and Marconi, 2006), as Europa is embedded within Jupiter's magnetosphere and experiencing an intense flux of charged particles $\left(\mathrm{H}^{+}, \mathrm{O}^{+}, \mathrm{S}^{+}, \mathrm{e}^{-}\right)$.

Using Galileo radio occultation observations, Kliore et al. (1997) found that a tenuous ionosphere exists on Europa. Observations have shown that the maximum electron density of about $10^{4} \mathrm{~cm}^{-3}$ exists near the surface, which suggests that the ionosphere is in contact with Europa's surface (Kliore et al., 1997; McGrath and Sparks, 2017). The ionosphere is not uniform across Europa's surface, the ionosphere profiles of different sites may vary considerably (McGrath et al., 2009). The maximum ionosphere is found to be geographically coincident with the intermittent water plumes (McGrath and Sparks, 2017), which have been detected to exist on Europa by Roth et al. (2014), Sparks et al. (2016), and Jia et al. (2018). This phenomenon implies that the water molecule plays an important role in the formation of Europa's ionosphere through multiple processes: photoionization, electron-impact ionization, charge transfer and a sequence of chemical reactions. Since the water column density is estimated to be $\sim 10^{16}$ to $10^{17} \mathrm{~cm}^{-2}$ (Roth et al., 2014; Sparks et al., 2017), the plumes would also result in efficient photolysis and electron-impact dissociation reactions of water molecules.

Based on a 1-D collisional Monte Carlo model, Shematovich and Johnson (2001) present the first simulation of the profile of Europa's tenuous oxygen atmosphere and build connection between the atmospheric composition and the surface source rate of $\mathrm{O}_{2}$. In an improved Monte Carlo model, Shematovich et al. (2005) include the surface source of $\mathrm{H}_{2} \mathrm{O}$ and simulate the compositions of Europa's atmosphere including $\mathrm{O}_{2}, \mathrm{H}_{2} \mathrm{O}, \mathrm{O}$ and $\mathrm{OH}$, which originate from a balance between sources from irradiation of the icy surface and losses induced by the magnetospheric plasma. Using a 2-D Direct Simulation Monte Carlo technique, Smyth and Marconi (2006) study all the water group species in Europa' atmosphere and their contribution to the gas torus. $\mathrm{H}_{2}$ and $\mathrm{O}$ are found to be the major compositions of the torus and their asymmetric

\footnotetext{
* Corresponding author.

E-mail address: jiazheng@caltech.edu (J. Li).
} 
distributions near Europa's orbit are simulated (Smyth and Marconi, 2006). Other than water group species, the distribution of trace constituents in Europa's atmosphere (e.g. Na, $\mathrm{K}, \mathrm{SO}_{2}, \mathrm{CO}_{2}$ ) and their potential implication on Europa's surface composition have been modelled by several studies (Johnson et al., 2002; Leblanc et al., 2002; Cassidy et al., 2009). Except for the regular surface sputtering sources, irregular eruption like the plumes may have huge impact on the local and global atmosphere. A recent study, Teolis et al. (2017) have evaluated the complex density and compositional structure of Europa's global exosphere under the influence of a south pole plume. Their results also provide potential guidance for future spacecraft flyby detections. However, no study has been conducted on the connection between plume and Europa's ionosphere and the influence of the ionized species on Europa's neutral atmosphere is not yet fully understood.

Due to the lack of studies on the ionization, photolysis and radiolysis of water molecules from Europa's plumes, we focus on analyzing these processes in this paper. Here we use a one-dimensional chemistrytransport model to investigate the influence of the plumes on the formation of Europa's atmosphere and ionosphere and try to enrich our knowledge on the coupling of the ionized and neutral species in Europa's atmosphere.

\section{Model description}

The model we applied to the atmosphere (ionosphere included) of Europa is the Caltech/JPL chemistry-transport model KINETICS (Allen et al., 1981; Yung and DeMore, 1999), which presented a stable solution for an atmosphere with surface pressures as low as $\sim 10^{-6} \mu$ bar (Yung and McElroy, 1977) on Ganymede. The details of the mechanism of the model can be found in Gladstone et al. (1996). The one-dimensional KINETICS model used in this study is modified from a more current version presented in Liang et al. (2005). Here we focus on simulating the atmosphere that is in the middle part of a steady plume, where horizontal diffusion of water molecules is assumed to be negligible and the time scale to reach the chemical equilibrium is less than the lifetime of the plume, so the one-dimensional model is suitable for our study. In the model, the atmosphere is divided into 50 layers, from the surface to an altitude of $500 \mathrm{~km}$. The temperature of the atmosphere is set to be 1000 $\mathrm{K}$ with a scale height of $\sim 200 \mathrm{~km}$ (McGrath et al., 2009). The chemical compositions in the modelled atmosphere are oxygen-containing and hydrogen-containing neutral particles and ions, e.g. $\mathrm{H}, \mathrm{O}, \mathrm{O}_{2}, \mathrm{H}_{2} \mathrm{O}, \mathrm{O}_{2}^{+}$, and $\mathrm{H}_{2} \mathrm{O}^{+}$. A quasi-neutral atmosphere is assumed in our model, in other words, the electron density always equals to the ion density.

Major chemical reactions and their rate coefficients are listed in Table 1, where minor reactions are not shown. The electron-impact ionization and dissociation reactions are primarily induced by the thermal electrons (temperature $\sim 20 \mathrm{eV}$ ) from Jupiter's magnetosphere (marked as $\mathrm{e}^{*}$ in Table 1) (Johnson et al., 2009). To better model the electron-impact reactions, we consider the existence of the ionopause, which is the position that external plasma flow from magnetosphere cannot further penetrate. Using a 3D hybrid model, Sittler Jr et al. (2013) propose that an ionopause exists on Europa at the altitude of $\sim 40 \mathrm{~km}$. Above the ionopause, the density of $\mathrm{e}^{*}$ is assumed to be 160 $\mathrm{cm}^{-3}$, which is the median electron density near Europa's environment derived by Bagenal et al. (2015). Below the ionopause, since the plasma flow which carries the magnetospheric thermal electrons stops (Sittler Jr et al., 2013), the density of the thermal electrons is assumed to be 0 . Meanwhile, the $\mathrm{O}_{2}^{+}$and $\mathrm{H}_{2} \mathrm{O}^{+}$that formed above the ionopause will be quickly lost due to the pickup effect of the plasma flow that has a velocity of $\sim 100 \mathrm{~km} / \mathrm{s}$. In our model, their lifetimes are set to be $2 \mathrm{~s}$. Also, radicals $(\mathrm{O}, \mathrm{H}$ and $\mathrm{OH})$ from radiolytic and photolytic dissociation of $\mathrm{O}_{2}$ and $\mathrm{H}_{2} \mathrm{O}$ are likely to have kinetic energy of several eVs (Smyth and Marconi, 2006), which is higher than their escape velocity. Therefore, in the model they are assumed to have a $50 \%$ escape probability. For the photoionization and photolysis processes, their reaction rates are calculated from a radiative transfer model. Reaction 19, the charge-
Table 1

A list of major reactions in our modelled atmosphere, including their rate coefficients and references. In this table, T represents the temperature of the atmosphere. $\mathrm{e}^{-}$represents the electrons generated locally and $\mathrm{e}^{*}$ represents the thermal electrons from the magnetosphere.

\begin{tabular}{lll}
\hline Reactions & Rate coefficients $^{\mathrm{a}}$ & References $^{\mathrm{b}}$ \\
\hline $1 . \mathrm{O}_{2}+\mathrm{h} \nu \rightarrow 2 \mathrm{O}$ & $1.6 \times 10^{-8}$ & 1,2 \\
$2 . \mathrm{O}_{2}+\mathrm{h} \nu \rightarrow \mathrm{O}+\mathrm{O}\left(^{1} \mathrm{D}\right)$ & $1.1 \times 10^{-8}$ & 1,2 \\
$3 . \mathrm{O}_{2}+\mathrm{h} \nu \rightarrow \mathrm{O}_{2}^{+}+\mathrm{e}^{-}$ & $4.1 \times 10^{-9}$ & 2 \\
$4 . \mathrm{O}_{2}+\mathrm{h} \nu \rightarrow \mathrm{O}^{+}+\mathrm{O}+\mathrm{e}^{-}$ & $3.2 \times 10^{-10}$ & 2 \\
$5 . \mathrm{O}+\mathrm{h} \nu \rightarrow \mathrm{O}^{+}+\mathrm{e}^{-}$ & $7.4 \times 10^{-10}$ & 1,2 \\
$6 . \mathrm{O}^{+}+\mathrm{O}_{2} \rightarrow \mathrm{O}_{2}^{+}+\mathrm{O}$ & $1.7 \times 10^{-11}$ & 1,2 \\
$7 . \mathrm{O}^{+}+\mathrm{e}^{-} \rightarrow \mathrm{O}$ & $1.4 \times 10^{-10} \mathrm{~T}^{-0.7}$ & 1,2 \\
$8 . \mathrm{O}_{2}^{+}+\mathrm{e}^{-} \rightarrow 2 \mathrm{O}$ & $1.1 \times 10^{-5} \mathrm{~T}^{-0.7}$ & 2,3 \\
$9 . \mathrm{H}_{2} \mathrm{O}+\mathrm{h} \nu \rightarrow \mathrm{H}+\mathrm{OH}$ & $2.3 \times 10^{-7}$ & 1,2 \\
$10 . \mathrm{H}_{2} \mathrm{O}+\mathrm{h} \nu \rightarrow 2 \mathrm{H}+\mathrm{O}$ & $1.0 \times 10^{-8}$ & 1,2 \\
$11 . \mathrm{OH}^{-} \mathrm{h} \nu \rightarrow \mathrm{H}+\mathrm{O}$ & $3.7 \times 10^{-7}$ & 1 \\
$12 . \mathrm{O}+\mathrm{OH} \rightarrow \mathrm{O}_{2}+\mathrm{H}$ & $2.2 \times 10^{-11} \mathrm{e}^{120 / \mathrm{T}}$ & 1,2 \\
$13 . \mathrm{H}_{2} \mathrm{O}+\mathrm{h} \nu \rightarrow \mathrm{H}_{2} \mathrm{O}^{+}+\mathrm{e}^{-}$ & $3.1 \times 10^{-9}$ & 1,2 \\
$14 . \mathrm{H}_{2} \mathrm{O}^{+}+\mathrm{e}^{-} \rightarrow \mathrm{O}+2 \mathrm{H}$ & $2.9 \times 10^{-7}$ & $4,5,6$ \\
$15 . \mathrm{H}_{2} \mathrm{O}^{+}+\mathrm{e}^{-} \rightarrow \mathrm{O}+\mathrm{H}_{2}$ & $4.7 \times 10^{-8}$ & $4,5,6$ \\
$16 . \mathrm{H}_{2} \mathrm{O}^{+}+\mathrm{e}^{-} \rightarrow \mathrm{OH}+\mathrm{H}$ & $8.9 \times 10^{-8}$ & $4,5,6$ \\
$17.2 \mathrm{OH} \rightarrow \mathrm{O}+\mathrm{H}_{2} \mathrm{O}$ & $4.2 \times 10^{-12} \mathrm{e}^{-240 / \mathrm{T}}$ & 1 \\
$18 . \mathrm{H}_{2} \mathrm{O}^{+}+\mathrm{O}_{2} \rightarrow \mathrm{O}_{2}^{+}+\mathrm{H}_{2} \mathrm{O}$ & $5.0 \times 10^{-9}$ & 7 \\
$19 . \mathrm{O}_{2}^{+}+\mathrm{O}_{2} \rightarrow \mathrm{O}_{2}(\mathrm{escape})+\mathrm{O}_{2}^{+}$ & $7.5 \times 10^{-11}$ & estimated \\
$20 . \mathrm{O}_{2}+\mathrm{e}^{*} \rightarrow \mathrm{O}+\mathrm{O}$ & $1.3 \times 10^{-8}$ & 8 \\
$21 . \mathrm{O}_{2}+\mathrm{e}^{*} \rightarrow \mathrm{O}_{2}^{+}+\mathrm{e}^{-}$ & $2.4 \times 10^{-8}$ & 8 \\
$22 . \mathrm{H}_{2} \mathrm{O}+\mathrm{e}^{*} \rightarrow \mathrm{OH}+\mathrm{H}$ & $3.8 \times 10^{-8}$ & 8 \\
$23 . \mathrm{H}_{2} \mathrm{O}+\mathrm{e}^{*} \rightarrow \mathrm{H}_{2} \mathrm{O}^{+}+\mathrm{e}^{-}$ & $2.3 \times 10^{-8}$ & 8 \\
\hline & &
\end{tabular}

${ }^{a}$ Units are $\mathrm{s}^{-1}$ for photochemical reactions and $\mathrm{cm}^{3} \mathrm{~s}^{-1}$ for two-body reactions. For photochemical reactions, their reaction rates are calculated from a radiative transfer model, their rate coefficients are given at the top of the model atmosphere.

b References: 1, see references of Moses et al. (2000); 2, see references of Yung and DeMore (1999); 3, Sheehan and St.-Maurice (2004); 4, Datz et al. (2000); 5, Mul et al. (1983); 6, Vejby-Christensen et al. (1997); 7, Le Teuff et al. (2000); 8, Johnson et al. (2009).

exchange reaction, describes the major loss mechanism for $\mathrm{O}_{2}$ in the atmosphere (Lucchetti et al., 2016): a fast $\mathrm{O}_{2}^{+}$exchanges its charge with a slow neutral $\mathrm{O}_{2}$ during a collision and forms a slow $\mathrm{O}_{2}^{+}$and a fast neutral $\mathrm{O}_{2}$, which has approximately the same energy as the original fast $\mathrm{O}_{2}^{+}$. If the original ion has the kinetic energy that is higher than the escape energy of Europa $(\sim 0.7 \mathrm{eV})$, the newly formed neutral $\mathrm{O}_{2}$ will be able to escape the atmosphere. According to Fig. 4 in Benyoucef and Yousfi (2014), the rate coefficient of this reaction is estimated to be $\sim 7.5 \times 10^{-10} \mathrm{~cm}^{3} \mathrm{~s}^{-1}$. However, only a part of the $\mathrm{O}_{2}^{+}$population has enough energy to complete this process. If the original ion does not have enough energy, this reaction will not change the composition of the atmosphere. Therefore, for the whole $\mathrm{O}_{2}^{+}$population, the rate coefficient of reaction 19 should be lower than $7.5 \times 10^{-10} \mathrm{~cm}^{3} \mathrm{~s}^{-1}$. Here we assume that about $10 \%$ of the $\mathrm{O}_{2}^{+}$are energetic ones and the rate coefficient is estimated to be $\sim 7.5 \times 10^{-11} \mathrm{~cm}^{3} \mathrm{~s}^{-1}$ (please refer to Section 4 for rationale for this estimate). The solar flux values are obtained from Mount and Rottman (1983), Torr and Torr (1985), and World Meteorological Organization (1985). Since the values from those references are corresponding to the Earth, which is $1 \mathrm{AU}$ (AU) from the Sun, the solar flux values at Europa are scaled according to the mean distance between the Sun and Europa, which is $\sim 5.2 \mathrm{AU}$. The solar zenith angle is set as $80^{\circ}$.

To evaluate the influence of water plume to the atmosphere, we first use KINETICS to construct a background $\mathrm{O}_{2}$-dominated atmosphere. For building this background atmosphere, the key boundary condition for the model is the net flux of $\mathrm{O}_{2}$ at the surface, which represents the intensity of the oxygen source and determines the $\mathrm{O}_{2}$ concentration in the atmosphere. In this study, the background $\mathrm{O}_{2}$ column density is set to be $\sim 3.5 \times 10^{14} \mathrm{~cm}^{-2}$ (Roth et al., 2014), corresponding to an $\mathrm{O}_{2}$ surface net flux of $\sim 1.9 \times 10^{9} \mathrm{~cm}^{-2} \mathrm{~s}^{-1}$. Since the influence of the plume to the intensity of the oxygen source at surface is negligible, we fix the $\mathrm{O}_{2}$ 
surface net flux and put water vapor into our model to construct plumecontrolled atmosphere. The $\mathrm{H}_{2} \mathrm{O}$ column density is set to be $\sim 1.5 \times 10^{16}$ $\mathrm{cm}^{-2}$ (Roth et al., 2014), which corresponds to an $\mathrm{H}_{2} \mathrm{O}$ density of $\sim 2.2$ $\times 10^{9} \mathrm{~cm}^{-3}$ at the surface. Comparing the profiles of neutral and ionized species between the background atmosphere and the plume-controlled atmosphere, we can examine the influence of the plume to Europa's atmosphere.

\section{Simulation results}

The density profiles of major neutral and ionized constituents in our model are shown in Fig. 1 and Fig. 2, respectively. In both figures, each solid line represents the profile of a constituent in the background atmosphere while each dashed line represents the profile of the same constituent in the plume-controlled atmosphere. Fig. 1 shows that in the plume-controlled atmosphere, $\mathrm{H}_{2} \mathrm{O}$ is the dominant species and $\mathrm{O}_{2}$ becomes a minor species. Compared to the background atmosphere, $\mathrm{O}_{2}$ density increases by less than a factor of 2 , which is consistent with the oxygen observation at the plume region described by Roth et al. (2014), who report no significant increase of $\mathrm{O}_{2}$ concentration near the plume. As for ionized species, Fig. 2 shows that in both background and plumecontrolled atmosphere, the highest ion density emerges near the surface, suggesting that the ionosphere is in contact with the surface. The surface ion density of the background atmosphere $\left(\sim 4 \times 10^{3} \mathrm{~cm}^{-3}\right)$ is consistent with the minimum surface electron density $\left(\sim 5 \times 10^{3} \mathrm{~cm}^{-3}\right)$ of the average ionosphere profile derived from the Galileo occultation observations (Kliore et al., 1997). In the plume-controlled atmosphere, the $\mathrm{O}_{2}^{+}$ is still the dominant ion species but only below $40 \mathrm{~km}$. The ion density at the surface is $\sim 1 \times 10^{4} \mathrm{~cm}^{-3}$, which is about a factor of 2.5 larger than the $\mathrm{O}_{2}^{+}$density in the background atmosphere. The shape of the modelled ionosphere profile is in good agreement with one of the maximum ionosphere profiles of Galileo occultation observations (shown as the black line in Fig. 2), which is detected near a potential plume location (McGrath and Sparks, 2017). Another interesting phenomenon found in our simulated plume-controlled atmosphere is that even though $\mathrm{H}_{2} \mathrm{O}$ is the dominant constituent, the $\mathrm{H}_{2} \mathrm{O}^{+}$concentration at the lower atmosphere is several orders of magnitude lower than the $\mathrm{O}_{2}^{+}$ concentration. The $\mathrm{H}_{2} \mathrm{O}^{+}$becomes the dominant species at higher altitude. The peak of the $\mathrm{H}_{2} \mathrm{O}^{+}$concentration, as well as the peak of the total ion density, appear at about $40 \mathrm{~km}$, instead of the surface. After carefully examining the chemical reactions happening in the atmosphere (as discussed below), this phenomenon can be understood.

Fig. 3 shows the reaction rate profiles of the most important reactions in the plume-controlled atmosphere. In the higher atmosphere, the

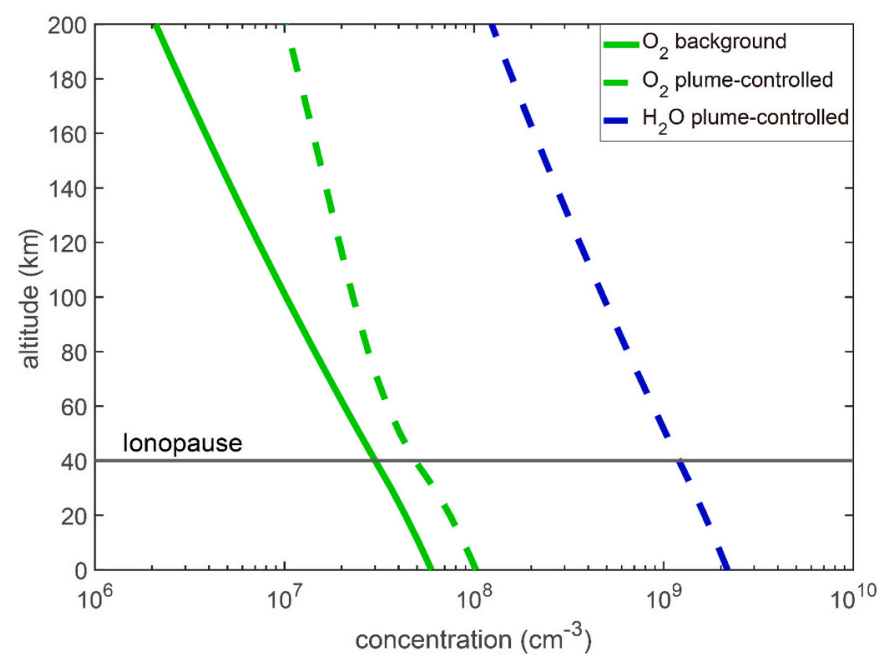

Fig. 1. Density profiles of the major neutral species in the background (solid line) and plume-controlled (dashed lines) atmosphere. electron-impact dissociation and ionization reactions are the dominant reactions for both $\mathrm{O}_{2}$ and $\mathrm{H}_{2} \mathrm{O}$, whose reaction rates are at least one order of magnitude higher than the rates of photolysis and photoionization. Photolysis and photoionization only dominate at lower altitude since the density of the magnetospheric thermal electron decrease abruptly at lower altitude. At lower altitude, the charge exchange reaction between $\mathrm{H}_{2} \mathrm{O}^{+}$and $\mathrm{O}_{2}$ (Reaction 18), which is shown as the pink dashed line in Fig. 3, is the major $\mathrm{H}_{2} \mathrm{O}^{+}$loss mechanism. This reaction suggests that the formation of the ionosphere is initiated by water photoionization and continued by charge transfer between water and oxygen molecules. Due to the large $\mathrm{O}_{2}$ density at the lower atmosphere, the lifetime of the water ion is very short, which explains the existence of the relatively low $\mathrm{H}_{2} \mathrm{O}^{+}$concentration at the lower atmosphere. Compared to the $\mathrm{O}_{2}$ photoionization reaction (Reaction 3, shown as the orange solid line in Fig. 3), the charge exchange reaction has a much higher reaction rate, which suggests that the charge exchange reaction is also the major $\mathrm{O}_{2}^{+}$production mechanism. At higher altitude, because the ionization rate of $\mathrm{H}_{2} \mathrm{O}$ is much higher than the ionization rate of $\mathrm{O}_{2}$ and the charge exchange reaction is depressed due to the decreasing $\mathrm{O}_{2}$ concentration, $\mathrm{H}_{2} \mathrm{O}^{+}$becomes the dominant ion species. In regard to the formation of oxygen molecules, the water dissociation processes (Reaction 9 and 22, shown as the dashed blue and green lines in Fig. 3) release a huge amount of $\mathrm{OH}$ into the atmosphere and accelerates the oxygen production reaction (Reaction 12, shown as the solid cyan line in Fig. 3). Although the existence of the plume increases the $\mathrm{H}_{2} \mathrm{O}^{+}$and $\mathrm{O}_{2}^{+}$ density in the atmosphere, which enhances the $\mathrm{O}_{2}$ loss through the two charge transfer reactions (Reaction 18 and 19), the $\mathrm{O}_{2}$ concentration still increases due to the water dissociation processes.

To understand the sensitivity of the atmosphere to the water concentration, we test two more cases with water column density of $\sim 5.0 \times$ $10^{15} \mathrm{~cm}^{-2}$ and $\sim 4.5 \times 10^{16} \mathrm{~cm}^{-2}$ (one third and three times of the column density derived by Roth et al. (2014)). The results of our sensitivity test are shown in Fig. 4 and Fig. 5. The density profiles of the neutral atmosphere show that in the upper atmosphere the $\mathrm{O}_{2}$ concentration is positively correlated to the water concentration, although the difference of $\mathrm{O}_{2}$ concentration between different cases are much less obvious than the difference of water concentration. In the lower atmosphere, the variation of the $\mathrm{O}_{2}$ concentration is considerably small and insensitive to the variation of the water concentration. The mechanism behind this phenomenon is intuitive: while the production of $\mathrm{O}_{2}$ is enhanced (depressed) by the increasing (decreasing) $\mathrm{H}_{2} \mathrm{O}$ dissociation, the $\mathrm{O}_{2}$ loss processes are also enhanced (depressed) by the increasing (decreasing) $\mathrm{H}_{2} \mathrm{O}$ ionization, so that the $\mathrm{O}_{2}$ concentration is not sensitive to different water concentrations. For the ionosphere profiles, we could see that at higher altitude, where the ionosphere is dominated by $\mathrm{H}_{2} \mathrm{O}^{+}$ ions, the ion density is proportional to the $\mathrm{H}_{2} \mathrm{O}$ density. In the case with excess water molecules, the maximum ion density appears at $40 \mathrm{~km}$, which is the same as the original case. However, in the lower altitude, both $\mathrm{H}_{2} \mathrm{O}^{+}$and $\mathrm{O}_{2}^{+}$densities of this case are lower than the original case. That's because in this case, the water plume is optically thick for the solar radiation so that the water photoionization rate decreases with decreasing altitude near the surface. In the case with less water molecules, because of the lower water concentration compared to the original case, the $\mathrm{H}_{2} \mathrm{O}^{+}$density depresses at higher altitude so that the maximum ion density exists at the surface instead of $40 \mathrm{~km}$. The comparison between these three cases confirms that the water molecule is the determinant species for the ionosphere profile.

\section{Summary and discussion}

Ever since the detection of intermittent water plumes on Europa, questions have been raised about the influence that the abrupt emergence of a huge amount of water would have on Europa's neutral atmosphere and ionosphere. In this study, we use the 1D chemicaltransport model KINETICS to investigate the role that water vapor plays in Europa's atmosphere. Our simulation results show that the 


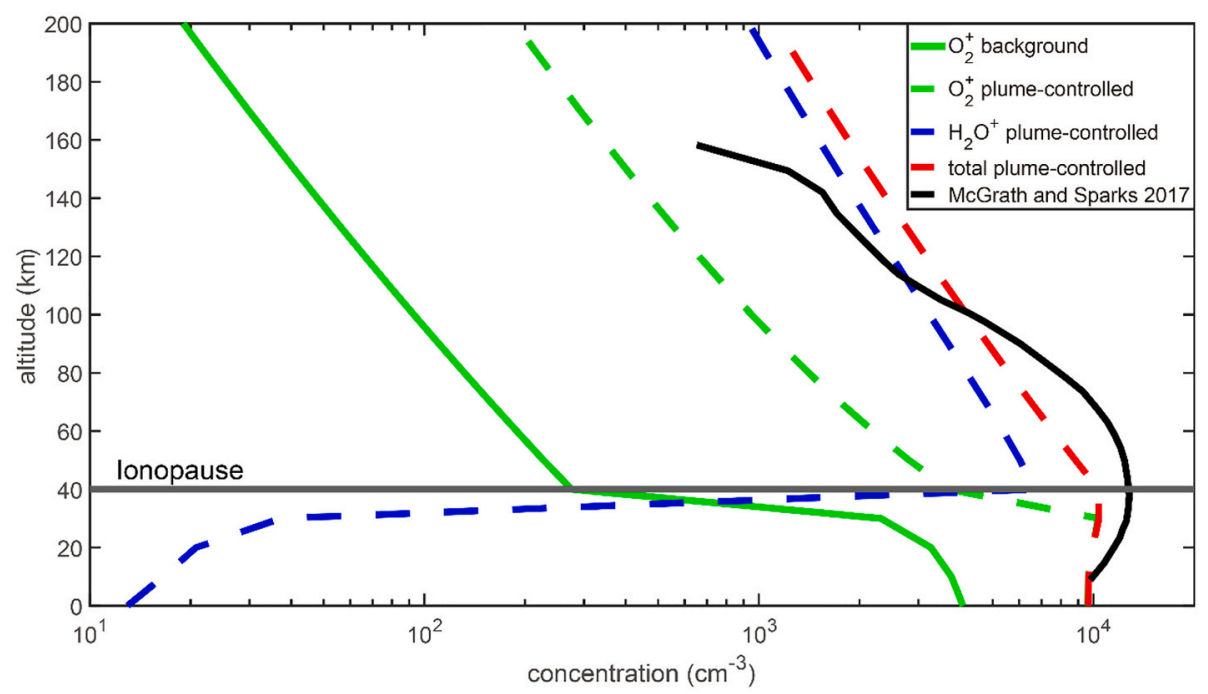

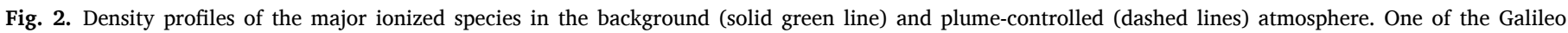

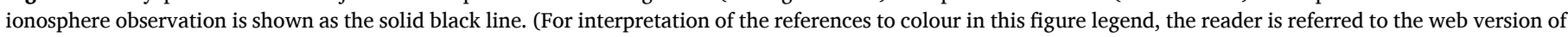
this article.)

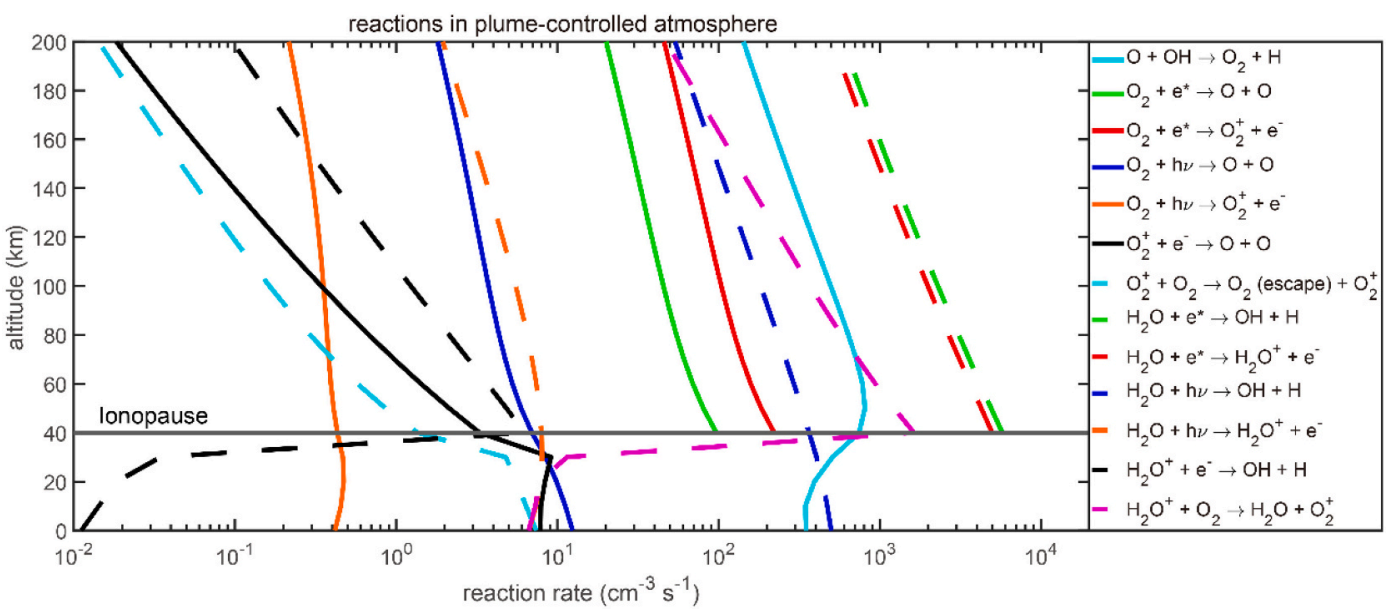

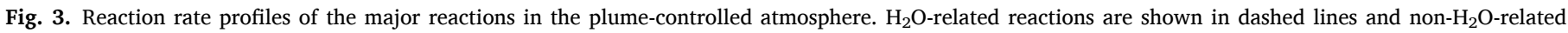
reactions are shown in solid lines. The reaction numbers (refer to Table 1 ) are written right next to the lines.

existence of water plume can increase the $\mathrm{O}_{2}$ concentration by about a factor of 2 due to water dissociation. Meanwhile, plume-generated water molecules are ionized by solar radiation and magnetospheric electrons. Charge transfer happens between oxygen molecules and water ions increases the $\mathrm{O}_{2}^{+}$concentration to about $10^{4} \mathrm{~cm}^{-3}$ near the surface. The simulated neutral atmosphere and ionosphere are both generally consistent with the observation, which implies the validity of our model.

To set up the background $\mathrm{O}_{2}$ atmosphere, we choose an $\mathrm{O}_{2}$ surface net flux in order to fit the observed atmosphere column density. The $\mathrm{O}_{2}$ surface net flux, which represents how many oxygen molecules are formed at the surface by ion sputtering processes, has been studies even before the detection of Europa's atmosphere (Johnson, 1990; Ip et al., 1998; Shematovich et al., 2005; Smyth and Marconi, 2006; Oza et al., 2018; Vorburger and Wurz, 2018). However, due to the lack of information about microscopic structure of surface ice and incoming ions, the intensity of the oxygen source at the surface is poorly constrained. Additionally, electrons, secondary electrons and photons produced by the incoming electrons (Gudipati et al., 2017) can penetrate into the surface ice, dissociate water molecules and produce radicals $(\mathrm{H}, \mathrm{O}, \mathrm{OH})$ inside the ice. These radicals can induce further chemical reactions inside the ice and form extra $\mathrm{O}_{2}$ which can diffuse out of the ice and form a part of the neutral atmosphere, providing us a second source of the oxygen other than the ion sputtering. Since the gravitational field of Europa is relatively weak, the oxygen atoms/molecules produced by ion sputtering are likely to escape into the magnetosphere, therefore the diffusion from the subsurface ice may be a stronger oxygen source than the ion sputtering. To the best of our knowledge, we are not aware of any published laboratory measurements that have quantified the emission of radicals $(\mathrm{H}, \mathrm{O}, \mathrm{OH})$ from ice under radiolysis. Studies on the oxygengeneration-related physical and chemical processes inside the ice are needed in the future to better constrain our modelling work on atmosphere.

Even though the simulation results agree well with the observations, further investigations are needed to improve our model. Reaction 19, the major $\mathrm{O}_{2}$ loss mechanism, is an important reaction in our model. Because $\mathrm{O}_{2}^{+}$is formed in the atmosphere and subsequently accelerated in the local fields of Europa (Sittler Jr et al., 2013; Lucchetti et al., 2016) and only a part of these ions attains escape energy of $0.7 \mathrm{eV}$. While we do not have any better estimates of $\mathrm{O}_{2}^{+}$velocity distribution near the surface, we take these studies as starting assumptions, based on which we estimate that about $10 \%$ of the $\mathrm{O}_{2}^{+}$are energetic enough for charge exchange driven $\mathrm{O}_{2}$ escape from the atmosphere, hence the rate coefficient 


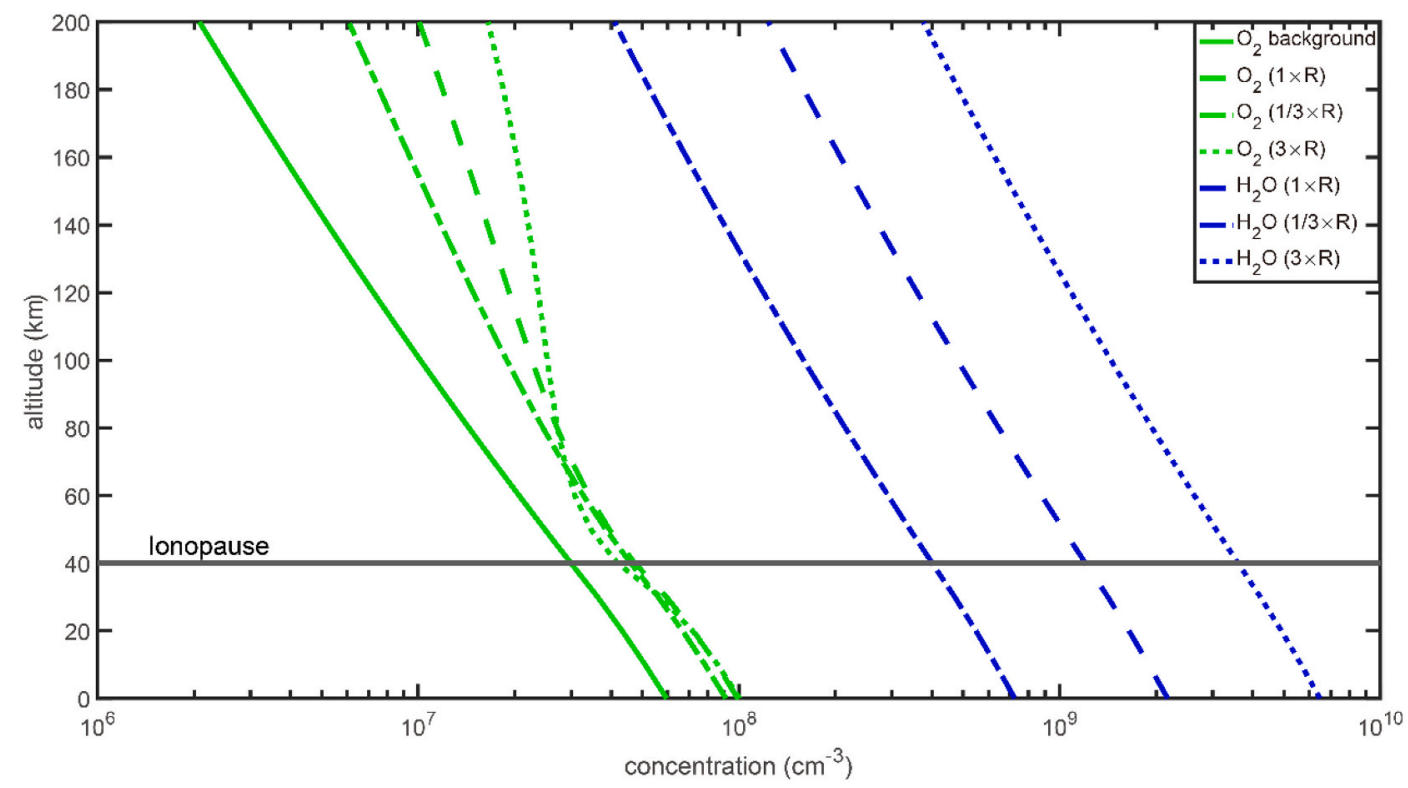

Fig. 4. Comparison of the major neutral species between the background and plume-controlled atmosphere with different water column densities (the $\mathrm{R}$ in the legend represents a water column density of $1.5 \times 10^{16} \mathrm{~cm}^{-2}$ ).

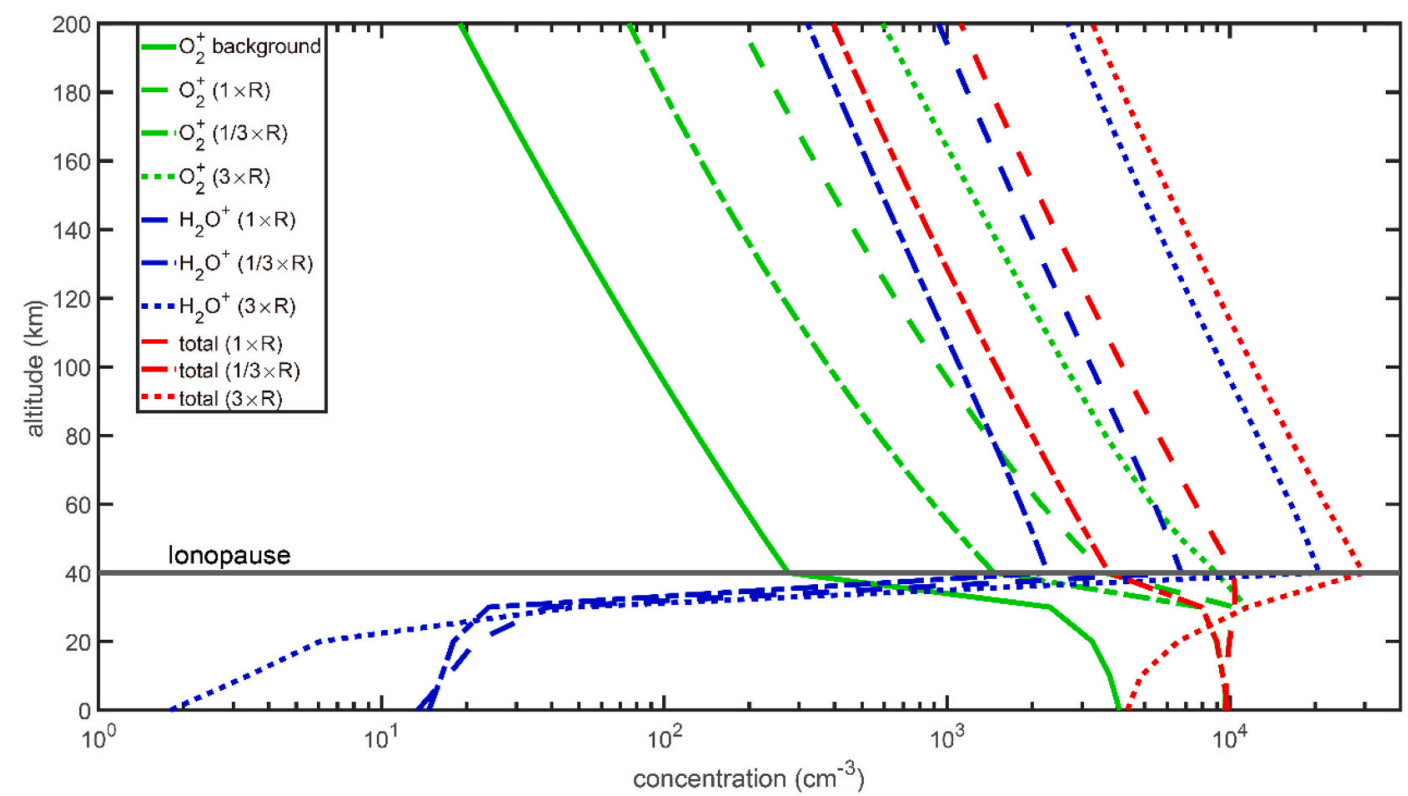

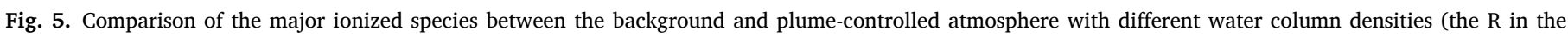
legend represents a water column density of $1.5 \times 10^{16} \mathrm{~cm}^{-2}$ ).

of reaction 19 in Table 1 is assumed to be $\sim 7.5 \times 10^{-11} \mathrm{~cm}^{3} \mathrm{~s}^{-1}$. Since this rate coefficient is strongly related to the energy distribution of $\mathrm{O}_{2}^{+}$, which is unknown and probably changes with altitude, our rate coefficient estimation might be different from the real value. However, we have tested different values for the $\mathrm{O}_{2}$ escape efficiency ( $1 \%, 10 \%$, and $100 \%$ ) and found that the influence of this rate on the overall $\mathrm{O}_{2}$ and $\mathrm{O}_{2}^{+}$ budget in the atmosphere of Europa is limited. Also, the sticking of radicals like $\mathrm{OH}, \mathrm{O}$ and $\mathrm{H}$ on Europa's surface is not considered in our model. Although there is no evidence that those radicals have high sticking coefficients on water ice, we should not exclude this possibility. If those radicals would stick effectively on the surface, their concentration on the atmosphere will be significantly depressed so that they will react on the surface rather than in the atmosphere. Despite the fact that our model is oversimplified in some aspects, our results successfully fit the previous Europa observations and show the interpretational power of the model. Future work considering those issues will help us build a more realistic model.

It should be noted that the plumes on Europa are intermittent, localized (Roth et al., 2014; Sparks et al., 2016) and models show that they have a specific umbrella-like canopy structure (Berg et al., 2016). Since we focus on the plume-controlled atmosphere, use a constant water column density and look for a stable solution, our model basically describes the atmosphere at the center of the water plume during its stable eruption time and our results rely on the assumption that all the chemical species are horizontally uniformly distributed in the middle part of the plume. The edge of the plume and the horizontal transport processes of the water molecules cannot be simulated by our current model. Therefore, a 2-D or 3-D chemical transport model, which will be 
developed in the future studies, is crucial to verify whether the assumption of horizontal uniformity is valid and to understand the influence of water plumes on the global atmosphere.

\section{Declaration of Competing Interest}

None.

\section{Acknowledgements}

We thank D. Shemansky for useful discussions. This research was supported in part by an NSF grant to Caltech. MSG thanks JPL for support through the JPL-Campus JROC program.

\section{References}

Allen, M., Yung, Y.L., Waters, J.W., 1981. Vertical transport and photochemistry in the terrestrial mesosphere and lower thermosphere (50-120 km). J. Geophys. Res. Space Physics 86, 3617.

Bagenal, F., Sidrow, E., Wilson, R.J., et al., 2015. Plasma conditions at Europa's orbit. Icarus 261, 1.

Benyoucef, D., Yousfi, M., 2014. Ar+/Ar, O2+/O2 and N2+/N2 elastic momentum collision cross sections: calculation and validation using the semi-classical model. Plasma Sci. Technol. 16, 588.

Berg, J.J., Goldstein, D.B., Varghese, P.L., et al., 2016. DSMC simulation of Europa water vapor plumes. Icarus 277,370 .

Brown, W.L., Augustyniak, W.M., Marcantonio, K.J., et al., 1984. Electronic sputtering of low temperature molecular solids. Nucl. Instrum. Methods Phys. Res., Sect. B 1, 307.

Cassidy, T.A., Johnson, R.E., Tucker, O.J., 2009. Trace constituents of Europa's atmosphere. Icarus 201, 182.

Datz, S., Thomas, R., Rosén, S., et al., 2000. Dynamics of three-body breakup in dissociative recombination: $\mathrm{H} 2 \mathrm{O}+$. Phys. Rev. Lett. 85, 5555.

Gladstone, G.R., Allen, M., Yung, Y.L., 1996. Hydrocarbon photochemistry in the upper atmosphere of Jupiter. Icarus 119, 1.

Gudipati, M., Henderson, B., Bateman, F., 2017. Effect of MeV Electron radiation on Europa's surface ice analogs. In: AAS/Division for Planetary Sciences Meeting, abstracts\# 49.

Hall, D.T., Strobel, D.F., Feldman, P.D., et al., 1995. Detection of an oxygen atmosphere on Jupiter's moon Europa. Nature 373, 677.

Hansen, C.J., Shemansky, D.E., Hendrix, A.R., 2005. Cassini UVIS observations of Europa's oxygen atmosphere and torus. Icarus 176, 305.

Ip, W.H., 1996. Europa's oxygen exosphere and its magnetospheric interaction. Icarus $120,317$.

Ip, W.H., Williams, D.J., McEntire, R.W., et al., 1998. Ion sputtering and surface erosion at Europa. Geophys. Res. Lett. 25, 829.

Jia, X., Kivelson, M.G., Khurana, K.K., et al., 2018. Evidence of a plume on Europa from Galileo magnetic and plasma wave signatures. Nat. Astron. 2, 459.

Johnson, R.E., 1990. Energetic Charged-Particle Interactions with Atmospheres and Surfaces, Vol. 19. Springer Science \& Business Media.

Johnson, R.E., Leblanc, F., Yakshinskiy, B.V., et al., 2002. Energy distributions for desorption of sodium and potassium from ice: the Na/K ratio at Europa. Icarus 156, 136.

Johnson, R.E., Burger, M.H., Cassidy, T.A., et al., 2009. Composition and Detection of Europa's Sputter-Induced Atmosphere, 507. Europa, University of Arizona Press, Tucson.

Kliore, A.J., Hinson, D.P., Flasar, F.M., et al., 1997. The ionosphere of Europa from Galileo radio occultations. Science 277, 355.
Le Teuff, Y.H., Millar, T.J., Markwick, A.J., 2000. The UMIST database for astrochemistry 1999. Astron. Astrophys. Suppl. Ser. 146, 157.

Leblanc, F., Johnson, R.E., Brown, M.E., 2002. Europa's sodium atmosphere: an ocean source? Icarus 159, 132.

Liang, M.C., Lane, B.F., Pappalardo, R.T., et al., 2005. Atmosphere of Callisto. Planets, Journal of Geophysical Research, p. 110.

Lucchetti, A., Plainaki, C., Cremonese, G., et al., 2016. Loss rates of Europa' s tenuous atmosphere. Planet. Space Sci 130, 14.

McGrath, M.A., Sparks, W.B., 2017. Galileo ionosphere profile coincident with repeat plume detection location at Europa. arXiv preprint 1 (1), 14 arXiv:1711.03628.

McGrath, M.A., Hansen, C.J., Hendrix, A.R., 2009. Europa. p.485. In: Pappalardo, Robert T., McKinnon, William B., Khurana, Krishan K. (Eds.), With the assistance of Ren'e Dotson with 85 Collaborating Authors. University of Arizona Press, Tucson.

Moses, J.I., Lellouch, E., Bézard, B., et al., 2000. Photochemistry of Saturn's atmosphere: II. Effects of an influx of external oxygen. Icarus 145, 166.

Mount, G.H., Rottman, G.J., 1983. The solar absolute spectral irradiance 1150-3173 A: may 17, 1982. J. Geophys. Res. Oceans 88, 5403.

Mul, P.M., McGowan, J.W., Defrance, P., et al., 1983. Merged electron-ion beam experiments. V. Dissociative recombination of $\mathrm{OH}+, \mathrm{H} 2 \mathrm{O}+, \mathrm{H} 3 \mathrm{O}+$ and $\mathrm{D} 3 \mathrm{O}+$. J. Phys. B: Atomic Mol. Phys. 16, 3099.

Oza, A.V., Johnson, R.E., Leblanc, F., 2018. Dusk/dawn atmospheric asymmetries on tidally-locked satellites: $\mathrm{O} 2$ at Europa. Icarus 305, 50.

Roth, L., Saur, J., Retherford, K.D., et al., 2014. Transient water vapor at Europa's south pole. Science $343,171$.

Roth, L., Saur, J., Retherford, K.D., et al., 2016. Europa's far ultraviolet oxygen aurora from a comprehensive set of HST observations. J. Geophys. Res. Space Physics 121, 2143.

Saur, J., Strobel, D.F., Neubauer, F.M., 1998. Interaction of the Jovian magnetosphere with Europa: constraints on the neutral atmosphere. J. Geophys. Res. Planets 103, 19947.

Sheehan, C.H., St.-Maurice, J. P., 2004. Dissociative recombination of N2+, O2+, and $\mathrm{NO}+$ : rate coefficients for ground state and vibrationally excited ions. J. Geophys. Res. Space Phys. 109.

Shemansky, D.E., Yung, Y.L., Liu, X., et al., 2014. A new understanding of the Europa atmosphere and limits on geophysical activity. Astrophys. J. 797, 84.

Shematovich, V.I., Johnson, R.E., 2001. Near-surface oxygen atmosphere at Europa. Adv. Space Res. 27, 1881.

Shematovich, V.I., Johnson, R.E., Cooper, J.F., et al., 2005. Surface-bounded atmosphere of Europa. Icarus 173, 480.

Sittler Jr., E.C., Cooper, J.F., Hartle, R.E., et al., 2013. Plasma ion composition measurements for Europa. Planet. Space Sci. 88, 26.

Smyth, W.H., Marconi, M.L., 2006. Europa's atmosphere, gas tori, and magnetospheric implications. Icarus 181, 510.

Sparks, W.B., Hand, K.P., McGrath, M.A., et al., 2016. Probing for evidence of plumes on Europa with HST/STIS. Astrophys. J. 829, 121.

Sparks, W.B., Schmidt, B.E., McGrath, M.A., et al., 2017. Active cryovolcanism on Europa? Astrophys. J. Lett. 839, L18.

Teolis, B.D., Wyrick, D.Y., Bouquet, A., et al., 2017. Plume and surface feature structure and compositional effects on Europa's global exosphere: preliminary Europa mission predictions. Icarus 284, 18.

Torr, M.R., Torr, D.G., 1985. Ionization frequencies for solar cycle 21: revised. J. Geophys. Res. Space Physics 90, 6675.

Vejby-Christensen, L., Andersen, L.H., Heber, O., et al., 1997. Complete branching ratios for the dissociative recombination of $\mathrm{H} 2 \mathrm{O}+, \mathrm{H} 3 \mathrm{O}+$, and CH3+. Astrophys. J. 483, 531.

Vorburger, A., Wurz, P., 2018. Europa's ice-related atmosphere: the sputter contribution. Icarus 311, 135.

World Meteorological Organization, 1985. Atmospheric Ozone vol. 1, Rep. 16, Geneva.

Yung, Y.L., DeMore, W.B., 1999. Photochemistry of Planetary Atmospheres. Oxford Univ. Press, New York, p. 258.

Yung, Y.L., McElroy, M.B., 1977. Stability of an oxygen atmosphere on Ganymede. Icarus $30,97$. 